\title{
Perspective
}

\section{Neural Substrates of Psychostimulant-Induced Arousal}

\author{
Craig W Berridge*, \\ 'Psychology Department, University of Wisconsin, Madison, WI, USA
}

\begin{abstract}
Extensive research has provided substantial insight into the neurobiological mechanisms underlying the reinforcing, locomotor-activating and stereotypy-inducing actions of psychostimulants. The diverse behavioral effects of these drugs are superimposed on potent arousalenhancing actions. Psychostimulant-induced arousal is a prominent contributing factor to the widespread use and abuse of these drugs. Moreover, enhanced arousal may be a critical component of the reinforcing and other behavioral actions of these drugs. Although long overlooked, recent work begins to identify the neural mechanisms involved in psychostimulant-induced arousal. For example, microdialysis studies demonstrate a close relationship between amphetamine-induced waking/arousal and amphetamine-induced increases in norepinephrine and dopamine efflux. Additionally, it is now clear that both norepinephrine and dopamine exert robust wakepromoting actions. The wake-promoting effects of norepinephrine involve synergistic actions of $\alpha_{1}$ - and $\beta$-receptors, whereas dopamineinduced waking involves both DI and D2 receptors. Finally, additional studies have identified subcortical regions involved in the wakepromoting actions of both norepinephrine and amphetamine. These regions include, but may not be limited to, the medial septal area, the medial preoptic area, and the lateral hypothalamus. Combined, these and other observations indicate a prominent involvement of both norepinephrine and dopamine in stimulant-induced arousal via actions within a network of subcortical regions. Although it is clear that both norepinephrine and dopamine contribute to psychostimulant-induced arousal, the degree to which each transmitter system is necessary for the expression of stimulant-induced arousal remains to be fully elucidated.

Neuropsychopharmacology (2006) 3 I, 2332-2340. doi:I 0. I038/sj.npp. I 30 I I59; published online 19 July 2006
\end{abstract}

Keywords: amphetamine; norepinephrine; dopamine; medial septal area; medial preoptic area; lateral hypothalamus

\section{INTRODUCTION}

Psychostimulants influence a variety of cognitive, affective, and motor processes. Extensive research conducted over the past three decades has provided substantial insight into the neurobiological mechanisms underlying the reinforcing, locomotor-activating and stereotypy-inducing actions of these drugs. The diverse behavioral effects of stimulants are superimposed on potent arousal-enhancing actions. The arousal-enhancing properties of psychostimulants are a prominent contributing factor to the widespread use and abuse of these drugs. Moreover, there exists a close relationship between arousal and state-dependent affective and cognitive processes (Bindra, 1968; Pribram and McGuinness, 1975). Thus, drug-induced arousal may well be an integral component of the broader spectrum of the behavioral actions of psychostimulants. Given the prominent nature of psychostimulant-induced arousal, it is surprising that little is known regarding the neural mechanisms underlying stimulant-induced arousal.

\footnotetext{
* Correspondence: Dr CW Berridge, Psychology Department, University of Wisconsin, Madison, WI 53706, USA, Tel: + I 608265 5938, Fax: + I 608262 4029, E-mail: Berridge@wisc.edu

Received 19 January 2006; revised 21 February 2006; accepted I March 2006

Online publication: 9 June 2006 at http://www.acnp.org/citations/ Npp060906060034/default.pdf
}

\section{NEUROBIOLOGY OF AROUSAL}

The term 'arousal' typically refers to the extent to which an organism is sensitive and/or responsive to information arising from the environment (Pribram and McGuinness, 1975). Across the sleep-wake cycle, large fluctuations in the sensitivity to sensory information are observed (Evarts, 1960; Pfingst et al, 1977; Bushnell et al, 1981). Further, within waking, sensitivity to environmental stimuli also varies, ranging from relative inattentiveness/insensitivity associated with drowsiness to extreme sensitivity (hypersensitivity) under conditions of intense arousal (Davis, 1997; Aston-Jones et al, 1998).

Changes in behavioral indices of arousal are accompanied by alterations in forebrain neuronal activity that are reflected in electroencephalographic (EEG) signals (TimoIaria et al, 1970; Vanderwolf and Robinson, 1981; Makeig and Inlow, 1993; McCormick and Bal, 1997). The formal examination of the neural mechanisms underlying arousal dates back to the work of Bremer (1937) and Moruzzi and Magoun (1949), which identified a critical role of the brainstem in arousal. To date, numerous systems have been identified that participate in the regulation of EEG and/or behavioral activity state, including brainstem (ie noradrenergic, serotonergic, cholinergic, hypocretin, etc) and basal forebrain systems (Foote et al, 1980; Hobson et al, 1975; Vanderwolf and Robinson, 1981; Metherate et al, 1992; O’Donnell, 2003; Steriade and Buzsaki, 1990; Buzsaki et al, 
1988; Berridge et al, 1996; Berridge and O'Neill, 2001; Sutcliffe and de Lecea, 2002).

\section{NORADRENERGIC AND DOPAMINERGIC MODULATION OF BEHAVIORAL STATE: OVERVIEW}

Stimulants increase extracellular levels of norepinephrine (NE), dopamine (DA), and to varying degree, serotonin (for a review see, Kuczenski and Segal, 1994). Importantly, the qualitative and quantitative neurochemical actions of these drugs are dependent on both the identity and dose of drug (Kuczenski and Segal, 1994). For example, cocaine potently affects serotonergic neurotransmission, whereas amphetamine (AMPH) increases extracellular serotonin levels only at moderately high doses and methylphenidate has minimal impact on serotonin across a broad range of doses (Kuczenski and Segal, 1997). Combined, these observations indicate that enhanced serotonergic neurotransmission is not an essential mechanism underlying the arousal-enhancing actions of psychostimulants, although this may contribute to the arousal-enhancing actions of certain stimulants.

Given that all psychostimulants target $\mathrm{NE}$ and DA neurotransmission, a critical first question becomes whether NE and DA exert arousal-enhancing actions. In examining the involvement of a neurotransmitter system in the regulation of behavioral state (or any other process), there are two potential general approaches. The first examines the effects of enhancing the activity of that neurotransmitter, whereas the second examines the effects of blocking the actions of that transmitter. Importantly, each approach addresses fundamentally distinct questions. In the first, the extent to which a transmitter is sufficient to induce a change in behavioral state is examined. In the second, the extent to which a transmitter is necessary for the maintenance of a behavioral state is examined. The neural regulation of arousal appears to involve substantial redundancy, with multiple systems exerting wake-promoting actions (Vanderwolf and Robinson, 1981; Pape and McCormick, 1989; Berridge and Waterhouse, 2003), and thus, inactivation of any single system often has minimal effects on sleep-wake state. This redundancy suggests that negative effects of neurotransmitter-selective antagonists and/or lesions on sleep and waking need to be interpreted cautiously.

\section{Noradrenergic Modulation of Behavioral State}

The locus coeruleus (LC) is the major source of brain NE (Foote et al, 1983). Synaptically released NE produces its effects in LC terminal fields via interactions with three major NE receptor subtypes: $\alpha_{1}, \alpha_{2}$, and $\beta . \alpha_{1}$ - and $\beta$ receptors are thought to exist primarily postsynaptically, whereas $\alpha_{2}$-receptors are present both pre- and postsynaptically. LC neurons display a tonic mode of discharge activity characterized by highly regular and state-dependent activity, with highest rates occurring during waking and lower rates during sleep (Hobson et al, 1975; Foote et al, 1980; Aston-Jones and Bloom, 1981). During waking, LC neurons discharge most rapidly in anticipation of EEG and

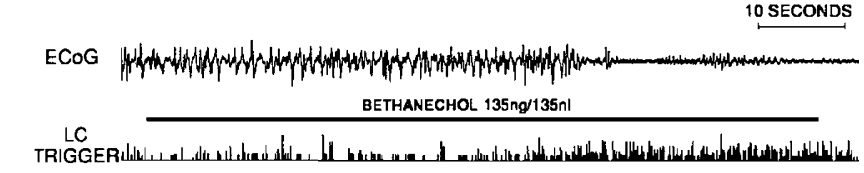

Figure I Relationship of LC neuronal discharge activity to cortical EEG activity before, during, and after peri-LC bethanechol infusions in the halothane-anesthetized rat. Bethanechol was infused 300-400 $\mu \mathrm{m}$ lateral to LC while LC neuronal activity was recorded. Simultaneously, EEG was recorded from the frontal cortex. EEG activity is shown in the top trace and the raw trigger output from LC activity in the bottom trace. Bethanechol infusion elicits an increase in LC discharge rate, which is readily apparent approximately two-thirds of the way through the 60-s infusion. Several seconds following LC activation, an abrupt onset of EEG desynchronization is observed (see Berridge and Foote, 1991).

behavioral changes that signal enhanced arousal or attentiveness (Foote et al, 1980; Aston-Jones and Bloom, 1981). Consistent with these observations, in vitro, NE induces a shift in activity patterns of cortical/thalamic neurons from a burst-mode typically associated with slow-wave sleep to a single spike-mode typically associated with waking (McCormick et al, 1991).

Combined, these observations suggest a causal role for the LC in the regulation of arousal/behavioral state. Consistent with this hypothesis, acute suppression of LC$\mathrm{NE}$ neurotransmission by systemic, i.c.v., or intra-brainstem administration of $\alpha_{2}$-agonists results in profound sedation (De Sarro et al, 1987; Gatti et al, 1988; Waterman et al, 1988). The small size of the LC and the close proximity of this nucleus to other brainstem arousal-related nuclei makes it difficult to determine unambiguously whether these drug-induced alterations in arousal involve actions on the LC-NE system or adjacent structures. To better address this issue, additional studies examined the effects of selective manipulation of LC neuronal activity on EEG indices of forebrain arousal in halothane-anesthetized rats. These studies utilized electrophysiological recordings to guide the placement of small infusions (35-150 nl) of pharmacological agents within close proximity to the LC to increase or decrease the rate of LC discharge activity (Adams and Foote, 1988). The effect of drug-induced alterations in LC neuronal discharge activity on forebrain EEG activity patterns was then examined (Berridge and Foote, 1991; Berridge et al, 1993). The close proximity of the infusion needle to the LC permits the use of small infusion volumes and thus limits the spread of drug beyond the LC. In these studies, unilateral LC activation produced a robust and relatively rapid (5-10 s) bilateral activation of forebrain EEG in the halothane-anesthetized rat (see Figure 1). This LC-dependent activation of forebrain EEG was prevented with i.c.v. pretreatment of a $\beta$-antagonist (Berridge and Foote, 1991). Conversely, bilateral suppression of LC neuronal discharge resulted in a robust increase in slowwave EEG activity under baseline conditions associated with EEG activation (ie lightly anesthetized preparation; Berridge et al, 1993). Importantly, even minimal LC neuronal discharge activity within a single hemisphere (ie $5-10 \%$ of basal levels) was sufficient to maintain bilaterally forebrain activation. This likely explains why LC/noradrenergic lesions, which almost certainly never reduce completely 

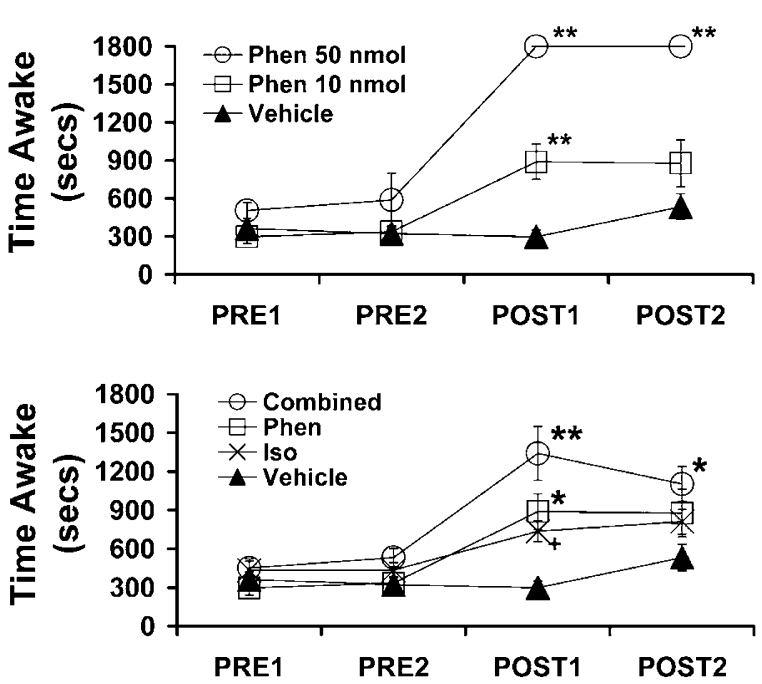

Figure 2 Additive wake-promoting effects of $\alpha \mid$ - and $\beta$-agonist infusion into the MSA. top panel displays the dose-dependent wake-promoting effects of the $\alpha_{1}$-agonist, phenylephrine (Phen; $10 \mathrm{nmol}, 50 \mathrm{nmol} / \mid 50 \mathrm{nl}$ ), infused into the MSA on total time spent awake as defined by combined EEG/EMG measures. bottom panel depicts the effects of $10 \mathrm{nmol}$ phenylephrine (Phen), $4 \mathrm{nmol}$ of the $\beta$-agonist, isoproterenol (Iso; $4 \mathrm{nmol}$ ), and combined phenylephrine and isoproterenol (Combined). The wakepromoting effects of isoproterenol and phenylephrine are additive. Symbols represent means $( \pm$ SEM) of time $(s)$ spent awake per 30-min testing epoch. PREI and PRE2 represent preinfusion portions of the experiment. POSTI-POST3 represent postinfusions epoch. $* P<0.0$ I compared to PREI; ${ }^{+} P<0.05$ compared to PREI (see Berridge et al, 2003).

extracellular NE levels (Abercrombie and Zigmond, 1989; Castaneda et al, 1990), do not result in large alterations in time spent awake (for a review see, Berridge and Waterhouse, 2003). Combined, these observations indicate that the LC is a potent modulator of forebrain and behavioral activity states.

\section{NE Acts at $\beta$ - and $\alpha_{1}$-Receptors Located Within the Medial Septal Area and the Medial Preoptic Area to Promote Alert Waking}

There exist a variety of cortical and subcortical sites where LC efferents might act to modulate forebrain EEG. Within the basal forebrain, the general regions of the medial septal area (MSA), the substantia innominata (SI), and the medial preoptic area (MPOA) participate in the regulation of forebrain EEG activity state (Buzsaki et al, 1983, 1988; Mohan et al, 1984; Metherate et al, 1992). Each of these regions receives LC-noradrenergic input (Cullinan and Zaborszky, 1991; Zaborszky et al, 1991; Swanson and Hartman, 1975; España and Berridge, 2006). Pharmacological mapping studies in unanesthetized, sleeping rats demonstrate robust dose-dependent and additive EEGactivating and wake-promoting actions of $\beta$ - and $\alpha_{1}$ receptor stimulation within the MSA and MPOA, but not the SI (Figure 2, also Figure 6; Berridge et al, 1996, 2003; Berridge and Foote, 1996; Berridge and O'Neill, 2001). Based on these observations, it is concluded that the activation of $\beta$ - and $\alpha_{1}$-receptors within the MSA and the MPOA likely contributes to stimulant-induced arousal. It is important to note that as used here, the terms MSA and MPOA refer to heterogeneous structures, each containing multiple subnuclei. The anatomical resolution of these previous mapping studies (approximately $500 \mu \mathrm{m}$ ) precludes identification of the specific subnuclei involved in the wakepromoting actions of $\mathrm{NE}$ within these general regions.

\section{$\beta$-Receptors are not Necessary for the Maintenance of Alert Waking}

The above-described observations demonstrate that the stimulation of MSA and MPOA $\beta$-receptors is sufficient to produce behavioral and forebrain EEG activation in anesthetized and unanesthetized animals. Moreover, in the anesthetized animal, both the global blockade of $\beta$-receptors, via i.c.v. infusions of a $\beta$-antagonist, and the selective blockade of MSA $\beta$-receptors, via intratissue infusions of a $\beta$-antagonist, decrease EEG activation under conditions of elevated LC discharge rates (Berridge and Wifler, 2000). These observations indicate that $\beta$-receptors, including the subset located within the MSA, are necessary for forebrain EEG activation under these conditions (ie in the presence of anesthesia; Berridge and Wifler, 2000).

In contrast, in the unanesthetized rat, neither i.c.v. infusions of a $\beta$-antagonist (Berridge and España, 2000) or bilateral blockade of MSA $\beta$-receptors reduce EEG and behavioral indices of arousal (Berridge and Wifler, 2000). As mentioned, in unanesthetized animals, the global suppression of LC-NE neurotransmission (using i.c.v. or intrabrainstem-administered $\alpha_{2}$-agonists) decreases EEG/ behavioral indices of arousal, indicating a necessary role for NE in normal arousal (De Sarro et al, 1988; Danysz et al, 1989). Combined, these observations indicate that in the unanesthetized animal, actions of other NE receptor subtypes (ie $\alpha_{1}$-receptors) make the arousal-promoting actions of $\beta$-receptors redundant in the unanesthetized animal (see 'Synergistic actions of $\beta$ - and $\alpha 1$-Receptors in the Maintenance of Alert Waking' below, for further discussion). It is important to emphasize that redundancy does not imply irrelevance: under normal conditions, stimulation of $\beta$-receptors (including MSA $\beta$-receptors) will promote alert waking, a functionally important action.

\section{The LC is not the Sole Source of Noradrenergic Innervation to the MSA and MPOA}

Evidence described above indicate that LC neurons exert robust modulatory actions on forebrain activity state and that this involves, at least in part, actions of $\mathrm{NE}$ within the MSA and MPOA. However, there are a number of noradrenergic nuclei that could also provide input to the MSA and MPOA, and thus could also promote the alert waking state. Recently completed retrograde tracing studies demonstrate that although the LC provides the majority of noradrenergic input to these three regions (approx. 50\%), lesser, although at times substantial, contributions arise from the A1/C1 (approx. 25\%) and A2/C2 (approx. 25-40\%) adrenergic cell groups (España and Berridge, 2006). In contrast, the subcoeruleus and A5 provide minimal input to the MSA and MPOA. Because these studies did not differentiate between adrenergic and noradrenergic cell bodies, these numbers likely overestimate the noradrenergic contribution from $\mathrm{A} 1 / \mathrm{C} 1$ and $\mathrm{A} 2 / \mathrm{C} 2$. Nonetheless, these observations indicate that a substantial proportion of 
noradrenergic input to the MSA and MPOA originates from outside the LC. Given the potent wake-promoting actions of MSA and MPOA NE receptors, it appears reasonable to conclude that $\mathrm{A} 1 / \mathrm{C} 1$ and $\mathrm{A} 2 / \mathrm{C} 2$ noradrenergic/adrenergic systems exert arousal-enhancing actions via projections to the MSA and MPOA. A logical extension of this conclusion is that stimulant-induced arousal likely involves actions of the $\mathrm{A} 1 / \mathrm{C} 1$ and $\mathrm{A} 2 / \mathrm{C} 2$ noradrenergic/adrenergic systems in addition to the LC-NE system.

\section{Additional Regions Involved in NE-Dependent Waking}

The observations reviewed above indicate a prominent role of the MSA and the MPOA in NE- and stimulant-induced arousal. However, numerous additional brain regions have been implicated in the regulation of arousal state. Included among these is the lateral hypothalamus ( $\mathrm{LH})$, a region that has long been hypothesized to play a role in the regulation of state and state-dependent processes, including motivation and reward (Stellar, 1954; Olds, 1962). More recently, it has been demonstrated that this region is the primary source for the peptide transmitter, hypocretin/orexin, which exerts robust wake-promoting actions when administered centrally (España et al, 2001; Sutcliffe and de Lecea, 2002). The LH receives a moderately dense noradrenergic innervation (Baldo et al, 2003), although most of this arises from outside the LC (Yoshida et al, 2005). In preliminary studies, we have observed wake-promoting actions of the $\alpha_{1}$-agonist, phenylephrine, when infused into the $\mathrm{LH}$, but not when infused immediately outside this region. These observations indicate that NE-dependent waking may well involve the LH. In addition to the MSA, MPOA, and LH, there are a number of regions that participate in the regulation of arousal level (ie central nucleus of the amygdala, tuberomammillary nucleus), all of which receive a relatively robust noradrenergic innervation. These observations indicate that both NE- and stimulant-induced arousal involve an extended network of multiple subcortical regions, the complete details of which remain to be determined.

\section{Synergistic Actions of $\beta$ - and $\alpha_{1}$-Receptors in the Maintenance of Alert Waking}

The above-reviewed observations indicate that stimulation of either $\alpha_{1}$ - or $\beta$-receptors is sufficient for the induction of alert waking. This raises the question of the extent to which the combined actions of these receptors are necessary for alert waking (ie contribute to the maintenance of the alert waking state). This question was addressed in studies that examined the EEG effects of $\beta$-receptor blockade (timolol, i.c.v.), $\alpha_{1}$-receptor blockade (prazosin, intraperitoneally), or both $\beta$ - and $\alpha_{1}$-receptor blockade under conditions associated with high arousal level (ie brightly lit novel environment; Berridge and España, 2000). When administered separately, $\beta$-receptor blockade has minimal effects on EEG and behavioral indices of arousal, whereas $\alpha_{1}$-receptor blockade results in an increase in sleep spindles (Figure 3; Buzsaki et al, 1991). In contrast, blockade of both $\beta$ - and $\alpha_{1}$ receptors results in a profound increase in large-amplitude, slow-wave EEG activity (Figure 3). Thus, combined blockade of $\beta$ - and $\alpha_{1}$-receptors exerts synergistic sedative effects.
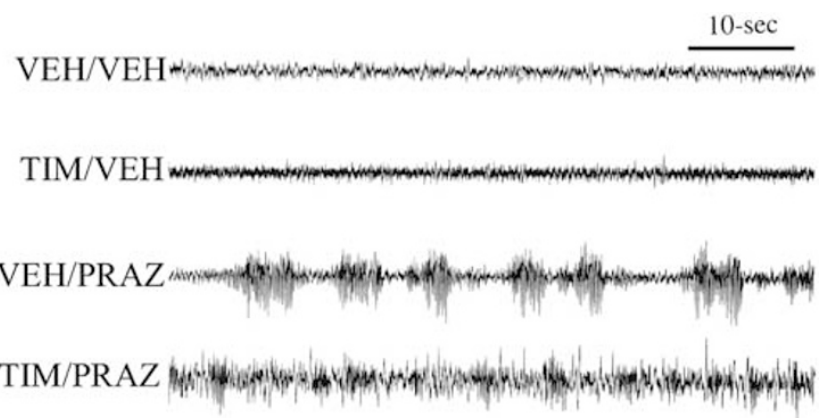

Figure 3 Synergistic sedative effects of $\alpha_{1}$ - and $\beta$-receptor blockade. Shown are the effects of the $\beta$-antagonist, timolol (i.c.v.), the $\alpha_{1}$-antagonist, prazosin (IP), and combined antagonist treatment on cortical EEG in animals exposed to an arousing brightly lit novel environment. Animals were treated 30-min before testing with: (I) I.c.v. vehicle + IP saline (VEH/ VEH); (2) $150 \mu$ g i.c.V. timolol + IP saline (TIM/VEH); (3) i.c.V. vehicle + $500 \mu \mathrm{g} / \mathrm{kg}$ prazosin (VEH/PRAZ); and (4) combined timolol + prazosin (TIM/PRAZ). In this figure, EEG traces are from the second 5-min epoch of exposure to the novel environment. Vehicle-treated controls displayed behavioral and EEG indices of alert waking throughout much of the recording session. This is reflected in sustained EEG desynchronization (low-amplitude, high-frequency). $\beta$-Receptor blockade alone (TIM/VEH) had no effects on EEG activity. $\alpha_{1}$-Receptor blockade alone (VEH/PRAZ) increased the frequency and duration of sleep spindles (high-voltage spindles). In contrast to that observed with $\beta$-receptor blockade alone, in the presence of $\alpha_{1}$-receptor blockade, $\beta$-receptor blockade produced substantial increases in large-amplitude, slow-wave activity (see Berridge and España, 2000)

Synergistic arousal-modulatory actions of $\alpha_{1^{-}}$and $\beta$ receptors could, in part, explain why earlier studies examining the effects of a single NE receptor antagonist failed to detect substantial alterations in psychostimulantinduced behavior. Importantly, the sedative effect of combined $\alpha_{1}$ - and $\beta$-receptor blockade was not observed during the first 5-min of testing. Thus, under certain conditions of elevated arousal, the combined activation of $\alpha_{1^{-}}$and $\beta$-receptors is not necessary for the maintenance arousal. The degree to which combined actions of $\alpha_{1}$ - and $\beta$ receptors is necessary for stimulant-induced arousal remains to be determined.

\section{Wake-Promoting Actions of DA}

Compared to the LC-NE system, less information exists regarding the degree to which central DA systems modulate behavioral state. Interestingly, midbrain DA neurons do not display robust alterations in firing rate between sleep and quiet waking (Steinfels et al, 1983; Trulson and Preussler, 1984). Nonetheless, rates of DA release within DA terminal fields fluctuate with sleep-wake state (Trulson, 1985; Smith et al, 1992; Feenstra et al, 2000). Moreover, systemic administration of D1 receptor agonists and antagonists increase and decrease, respectively, time spent awake (Monti et al, 1990; Trampus et al, 1991). D2 receptor agonists exert more complex effects, likely reflecting both presynaptic and postsynaptic functions of this receptor family (Monti et al, 1989; Python et al, 1996; Lagos et al, 1998; Olive et al, 1998). When administered centrally (i.c.v.) in sleeping rats, the D1 agonist, SKF-82958, and the D2 agonist, quinpirole, produce dose-dependent increases in time spent awake and suppress REM and slow-wave sleep in 


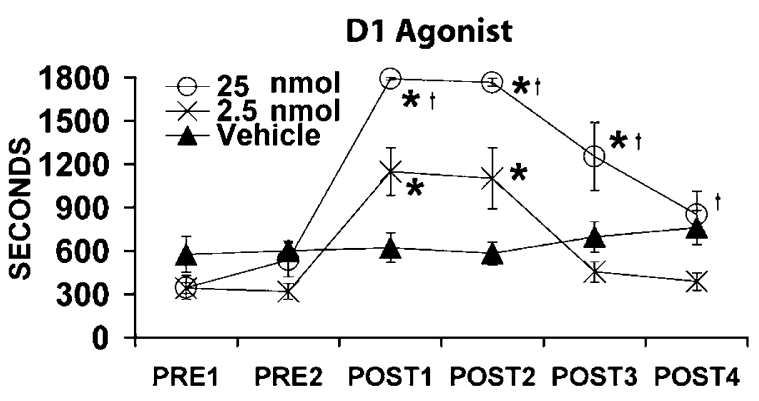

\section{D2 Agonist}

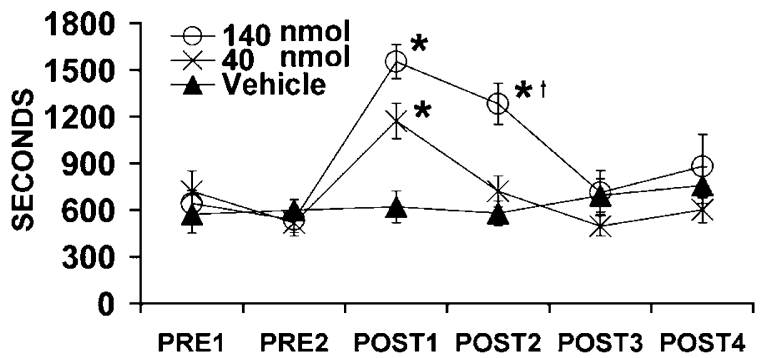

Figure 4 Effects of Dl-receptor and D2-receptor (bottom panel) stimulation on EEG/EMG-defined waking. Shown are the effects of i.c.v. vehicle and 2.5 or $25 \mathrm{nmol}$ of the DI agonist, SKF-82958 (top panel) and i.c.v. vehicle and 40 or $140 \mathrm{nmol}$ of the D2 agonist, quinpirole, on time spent awake. Symbols represent mean $( \pm$ SEM) time spent in a given behavioral state per 30-min epoch. PREI and PRE2 represent preinfusion and POSTI-POST4 represent postinfusion epochs. Both the DI and D2 agonist produced dose-dependent increases in time spent awake. $* P<0.05$ compared with vehicle-treated controls. ${ }^{\dagger} P<0.05$ compared with the low dose of the respective drug (see Isaac and Berridge, 2003).

the absence of locomotor activation (Figure 4; Isaac and Berridge, 2003). Given stimulants enhance DA efflux widely throughout the brain; these and other observations (Nishino et al, 1998; Wisor et al, 2001) suggest a prominent role of DA in the wake-promoting actions of these drugs.

\section{INVOLVEMENT OF NE AND DA IN STIMULANT-INDUCED AROUSAL}

Available evidence indicates wake-promoting actions of both NE and DA. Given the robust actions of psychostimulants on $\mathrm{NE}$ and DA neurotransmission, this in turn provides strong evidence for the involvement of both $\mathrm{NE}$ and DA in the arousal-enhancing actions of psychostimulants. Nonetheless, delineating the relative contribution of $\mathrm{NE}$ and/or DA in stimulant-induced arousal is particularly challenging for a number of reasons. First, systemic administration of $\mathrm{NE}$ and $\mathrm{DA}$ antagonists can influence behavioral state via peripheral actions. Further, given that multiple NE and DA receptors exert wake-promoting actions, blocking the actions of a single receptor may not impact substantially stimulant-induced arousal. Similarly, given a variety of regions appear to participate in stimulantinduced arousal, blocking the actions of $\mathrm{NE}$ and/or DA within a single region may not have a material impact on the arousal-enhancing actions of these drugs. Nonetheless, as reviewed below, limited observations collected to date provide evidence for a role of both NE and DA in stimulantinduced arousal.

\section{AMPH Acts within the Basal Forebrain to Increase Arousal}

Given that NE $\alpha_{1}$ - and $\beta$-receptors act within the MSA and MPOA to promote waking, it was proposed that these regions participate in psychostimulant-induced arousal. Consistent with this hypothesis, AMPH infusion into, but not outside (including SI), these regions elicits sustained increases in EEG and behavioral indices of arousal/waking (Figure 5; Berridge et al, 1999). For both the MSA and MPOA, the arousal-enhancing actions of AMPH were dosedependent (Berridge et al, 1999). Relative to unilateral infusions, bilateral infusions produced greater behavioral activation. At the lower dose of AMPH tested, AMPHinduced waking appeared to resemble normal waking, and was not associated with increases in locomotor activity or stereotypy. In contrast, bilateral infusions of the highest dose examined produced substantial increases in locomotor activity. In preliminary studies, we have also observed wake-promoting actions of AMPH when infused into the LH (data not shown). Combined, these observations indicate psychostimulant-induced arousal involves an extended network of subcortical sites that include, but is unlikely limited to (see above), the MSA, MPOA, and LH.

\section{AMPH-Induced Increases in Arousal and NE and DA Release are Closely Related}

If $\mathrm{NE}$ and/or DA participate in stimulant-induced arousal, there should be a close relationship between stimulantinduced alterations in NE/DA efflux and arousal. In vivo microdialysis studies demonstrate the existence of just such a relationship for both NE and DA (Berridge and Stalnaker, 2002). In these studies, low doses of AMPH $(0.15,0.25 \mathrm{mg} /$ $\mathrm{kg}$ ) that promote waking but do not produce locomotor activation/stereotypy produced prominent increases in extracellular levels of NE within the PFC that were closely associated with drug-induced increases in time spent awake (Figure 6). PFC DA was not as responsive as PFC NE to mild arousal produced by brief handling of the animal or during the earliest periods of AMPH-induced waking. Nonetheless, in general, there was a close relationship between AMPHinduced waking and $\mathrm{AMPH}$-induced increases in PFC DA efflux (Figure 6). Overall, these studies support the hypothesis that the arousal-enhancing actions of low-dose psychostimulants, in part, derive from stimulant-induced increases in NE and DA release.

These studies measured NE and DA efflux within the PFC because the PFC receives a noradrenergic innervation solely from the LC and because evidence suggests that at higher doses, stimulants produce comparable actions on NE/DA efflux across distinct catecholaminergic terminal fields. However, it was recently observed that at low doses that do not promote waking, the stimulant, methylphenidate, increases NE and DA efflux within the PFC while having minimal effects on subcortical NE (MSA) and DA (accumbens) efflux (Berridge et al, 2006). At modestly higher doses associated with moderate increases in time spent awake, more prominent increases in $\mathrm{NE}$ and $\mathrm{DA}$ efflux were observed outside the PFC. Combined, these observations suggest that (1) low-dose stimulants can preferentially target NE/DA neurotransmission within the PFC, and (2) 


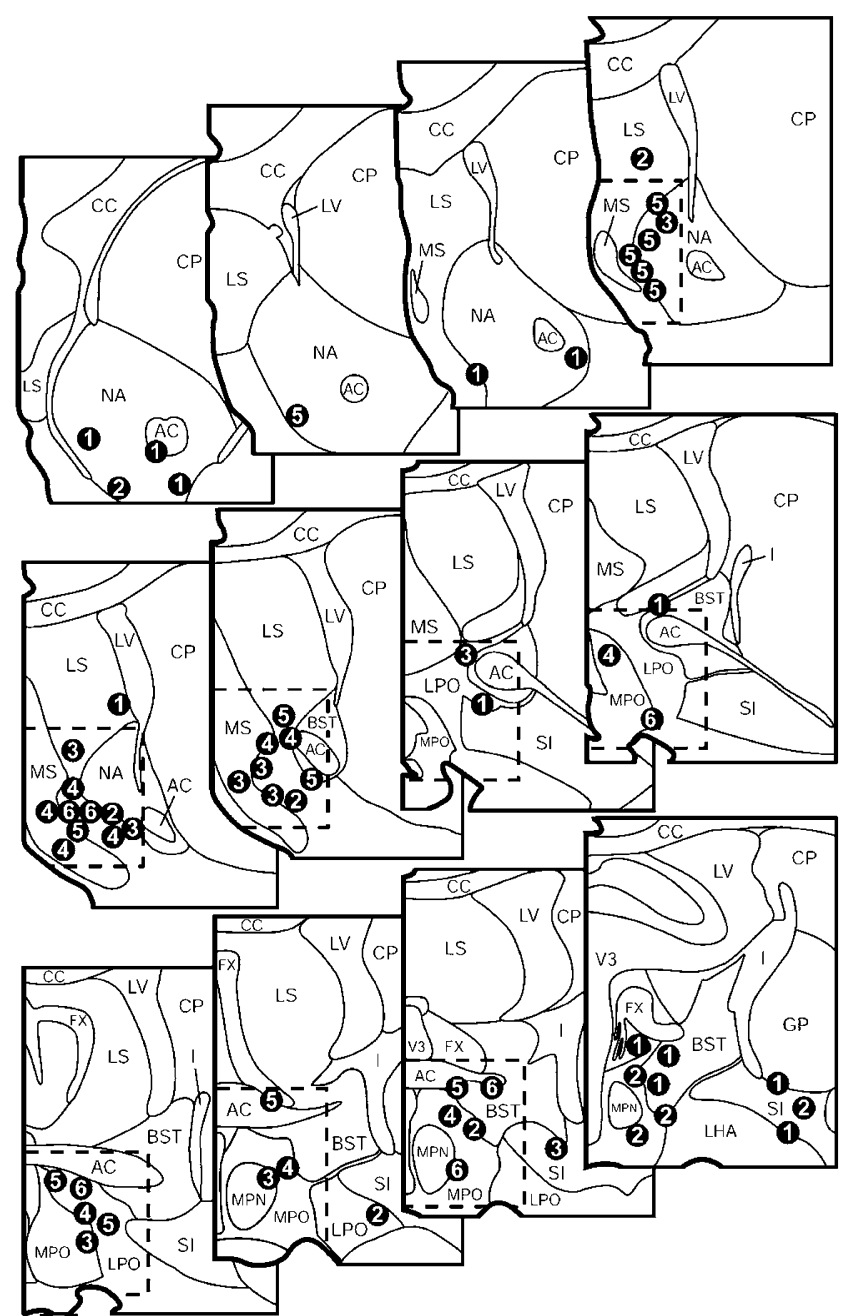

Figure $5 \mathrm{AMPH}$ acts within the MSA and MPOA to promote waking. Schematic depiction of the location of each unilateral $3.75 \mu \mathrm{g}$ AMPH infusion in the unanesthetized rat, with a numeral indicating the magnitude of the effect of each infusion on total time spent awake. Numerals specify the time range $(|=0-400 \mathrm{~s} ; 2=40|-800 \mathrm{~s} ; 3=80|-| 200 \mathrm{~s} ; 4=120 \mid-$ $1600 \mathrm{~s} ; 5=|60|-2000 \mathrm{~s} ; 6>2000)$ for time spent awake during the 60 min postinfusion interval for each animal. Vehicle-treated animals displayed a mean total time awake in this period of $35 \mathrm{I} \pm 46 \mathrm{~s}$. These infusions identify a region within which $\mathrm{AMPH}$ infusions increase waking, which encompasses the medial septum, the vertical limb of the diagonal band of Broca, the posterior portions of the shell region of the nucleus accumbens, and the preoptic area of the hypothalamus. This region is identified by the dotted line border. Infusions outside this region were substantially less effective at increasing waking, including within the SI. Panels are arranged anterior-posterior with the anterior-most panel shown in the upper left and the posterior-most panel shown in the bottom right position. AC, anterior commissure; BST, bed nucleus of the stria terminalis; CC, corpus callosum; CP, caudate-putamen; GP, globus pallidus; I, internal capsule; LS, lateral septum, LC, lateral ventricle; MS, medial septum; NA nucleus accumbens; NDB, nucleus of the diagonal band; SI, substantia innominata (see Berridge et al, 1999).

stimulant-induced arousal is more closely linked to stimulant-induced alterations in NE and DA neurotransmission outside the PFC, particularly within select subcortical regions (ie MSA, MPOA, LH). It is possible that a failure to significantly impact subcortical NE neurotransmission could, at least in part, explain why wake-promoting actions have not been observed with all NE reuptake
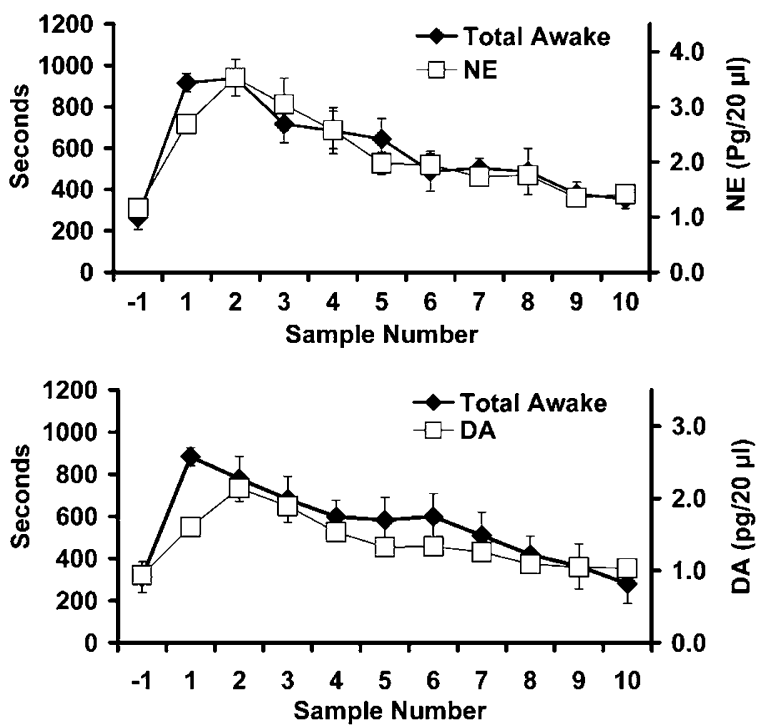

Figure 6 Relationship between AMPH-induced increases in waking and AMPH-induced increases in extracellular levels of NE and DA (bottom panel). Unanesthetized animals were treated with $0.15 \mathrm{mg} / \mathrm{kg}$ (subcutaneously) AMPH. Shown are the NE (top panel) and DA (bottom panel) levels $(\mathrm{pg} / 20 \mu \mathrm{l})$ from I5-min dialysate samples and time spent awake. Scales have been adjusted to permit the superimposition of NE and waking data from baseline and recovery portions of the AMPH response. There was a close relationship between $\mathrm{AMPH}$-induced changes in waking and NE and DA levels (see Berridge and Stalnaker, 2002).

blockers (ie if the dose was too low to increase NE efflux within these subcortical regions; Nishino et al, 1998).

\section{Is AMPH-Induced Arousal Dependent on NE?}

The above-reviewed information indicates that stimulantinduced increases in NE neurotransmission contribute to stimulant-induced arousal. Unaddressed in this work is the degree to which NE is necessary for full expression of stimulant-induced arousal. As an initial step in testing the hypothesis that NE is indeed necessary for AMPH-induced arousal, the effects of i.c.v. pretreatment with the $\beta$ antagonist, timolol, on intravenous (i.v.) AMPH $(0.15 \mathrm{mg} /$ $\mathrm{kg}$ )-induced EEG activation were examined in halothaneanesthetized rats (Berridge and Morris, 2000). It was observed that timolol pretreatment dose-dependently blocked AMPH-induced EEG activation (Figure 7). Thus, in the anesthetized animal, blockade of central $\beta$-receptors is sufficient to block the EEG activating effects of systemic AMPH. The effects of $\beta$-antagonist on AMPH-induced arousal in the unanesthetized animal remain to be examined. However, the above-described observations indicate that in contrast to anesthetized animals, $\beta$-receptor blockade alone does not reduce EEG or behavioral indices of arousal in unanesthetized animals. Therefore, it is predicted that $\beta$-receptor blockade alone will not alter AMPH-induced arousal in the unanesthetized animal. However, given the sedative effects of combined blockade of both $\alpha_{1}$ - and $\beta$-receptors in unanesthetized animals, it is quite possible that combined actions of these two receptors is necessary for full expression of stimulant-induced arousal. 


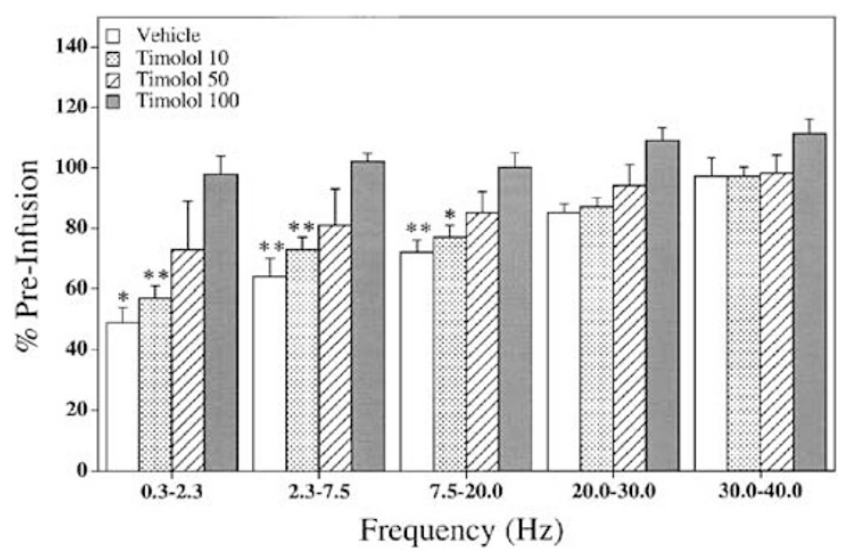

Figure $7 \quad \beta$-Receptor blockade prevents AMPH-induced EEG activation. Shown are the effects of varying dose of the $\beta$-antagonist, timolol, on i.v. AMPH $(0.15 \mathrm{mg} / \mathrm{kg})$-induced alterations in power of selected frequency bands in cortical EEG as determined by power-spectral analyses. The percentage of preinfusion means $( \pm S E M)$ of the power of the specified frequency bands is shown. When administered 30-min following i.c.v. vehicle pretreatment, i.v. AMPH decreased the absolute power of the 0.3 2.3 (slow wave), $2.3-7.5$, and $7.5-20.0 \mathrm{~Hz}$ frequency bands (ie EEG activation). I.c.v. pretreatment with timolol produced a dose-dependent blockade of the AMPH induced EEG activation. $* P<0.05$, $* * P<0.0$ I significantly different from preinfusion epochs (see Berridge and Morris, 2000).

\section{Is AMPH-Induced Arousal Dependent on DA?}

Direct stimulation of NE receptors within a variety of subcortical regions promotes alert waking. Thus, it is likely that NE contributes to stimulant-induced arousal. However, previous studies demonstrate that the deletion of the DA transporter (DAT) gene in mice prevents the wakepromoting effects of methamphetamine (Wisor et al, 2001). Combined, these observations could indicate that stimulant-induced increases in extracellular levels of DA are necessary for the expression of NE receptor-dependent waking. However, this hypothesis is hard to reconcile with robust wake-promoting actions of intratissue infusions of direct acting NE agonists, which presumably occur in the absence of drug-induced increases in DA neurotransmission. Alternatively, as described above, stimulant-induced arousal likely involves the actions of NE and DA outside the PFC. For example, at low doses, methylphenidate preferentially targets NE and DA neurotransmission within the PFC and this is associated with minimal increases in time spent awake (Berridge et al, 2006). Given the mild wakepromoting effects observed in wild-type animals in the DAT knockout study (an increase of 60 -min over a 5 -h period), the dose of methamphetamine used in this study appears relatively low. Therefore, it is possible that this relatively low dose of methamphetamine had a minimal impact on extracellular NE levels outside the PFC. It will be important for future studies to determine the degree to which both NE and DA are necessary for the arousalenhancing actions of psychostimulants.

\section{SUMMARY}

Despite the robust and well-documented arousal-enhancing effects of psychostimulants, surprisingly little is known regarding the neural mechanisms underlying these actions. Available evidence indicates prominent arousal-enhancing actions of both NE and DA via action within a variety of subcortical sites, including the MSA, MPOA, and LH. Given stimulants enhance NE and DA efflux, these observations indicate a prominent role of both NE and DA acting in these subcortical sites in stimulant-induced arousal. Consistent with this hypothesis, stimulant-induced arousal appears to be closely related to drug-induced alterations in NE and DA efflux within these subcortical regions. Moreover, when infused directly into these subcortical regions, AMPH exerts robust wake-promoting actions. Combined, the available evidence indicates that psychostimulant-induced arousal is dependent on the actions of both NE and DA within a widely distributed network of subcortical regions.

\section{ACKNOWLEDGEMENTS}

This work is dedicated to the memory of Dr David Segal, a gifted scientist and advisor. I am grateful to have had the opportunity to benefit from his generosity, energy, and vast knowledge about the behavioral neurobiology of catecholamines and psychostimulants. Preparation of this manuscript and some of the research described was supported by PHS Grants MH62359, DA10681, and DA00389.

\section{REFERENCES}

Abercrombie ED, Zigmond MJ (1989). Partial injury to central noradrenergic neurons: reduction of tissue norepinephrine content is greater than reduction of extracellular norepinephrine measured by microdialysis. J Neurosci 9: 4062-4067.

Adams LM, Foote SL (1988). Effects of locally infused pharmacological agents on spontaneous and sensory-evoked activity of locus coeruleus neurons. Brain Res Bull 21: 395-400.

Aston-Jones G, Bloom FE (1981). Activity of norepinephrinecontaining locus coeruleus neurons in behaving rats anticipates fluctuations in the sleep-waking cycle. J Neurosci 1: 876-886.

Aston-Jones G, Rajkowski J, Ivanova S, Usher M, Cohen J (1998). Neuromodulation and cognitive performance: recent studies of noradrenergic locus coeruleus neurons in behaving monkeys. Adv Pharmacol 42: 755-759.

Baldo BA, Daniel RA, Berridge CW, Kelley AE (2003). Overlapping distributions of orexin/hypocretin- and dopamine-beta-hydroxylase immunoreactive fibers in rat brain regions mediating arousal, motivation, and stress. J Comp Neurol 464: 220-237.

Berridge CW, Bolen SJ, Manley MS, Foote SL (1996). Modulation of forebrain electroencephalographic activity in halothane- anesthetized rat via actions of noradrenergic beta-receptors within the medial septal region. J Neurosci 16: 7010-7020.

Berridge CW, España RA (2000). Synergistic sedative effects of noradrenergic alpha(1)- and beta-receptor blockade on forebrain electroencephalographic and behavioral indices. Neuroscience 99: 495-505.

Berridge CW, Foote SL (1991). Effects of locus coeruleus activation on electroencephalographic activity in neocortex and hippocampus. J Neurosci 11: 3135-3145.

Berridge CW, Foote SL (1996). Enhancement of behavioral and electroencephalographic indices of waking following stimulation of noradrenergic beta-receptors within the medial septal region of the basal forebrain. J Neurosci 16: 6999-7009.

Berridge CW, Isaac SO, España RA (2003). Additive wakepromoting actions of medial basal forebrain noradrenergic alpha1- and beta-receptor stimulation. Behav Neurosci 117: 350-359. 
Berridge CW, Morris MF (2000). Amphetamine-induced activation of forebrain EEG is prevented by noradrenergic beta-receptor blockade in the halothane-anesthetized rat. Psychopharmacology (Berlin) 148: 307-313.

Berridge CW, O'Neil J, Wifler K (1999). Amphetamine acts within the medial basal forebrain to initiate and maintain alert waking. Neuroscience 93: 885-896.

Berridge CW, O'Neill J (2001). Differential sensitivity to the wakepromoting actions of norepinephrine within the medial preoptic area and the substantia innominata. Behav Neurosci 115: 165-174.

Berridge CW, Page ME, Valentino RJ, Foote SL (1993). Effects of locus coeruleus inactivation on electroencephalographic activity in neocortex and hippocampus. Neuroscience 55: 381-393.

Berridge CW, Devilbiss DM, Andrzejewski ME, Arnsten AFT, Kelley AE, Schmeichel B et al (2006). Methylphenidate preferentially increases catecholamine neurotransmission within the prefrontal cortex at low doses that enhance cognitive function. Biol Psychiat [Epub ahead of print].

Berridge CW, Stalnaker TA (2002). Relationship between low-dose amphetamine-induced arousal and extracellular norepinephrine and dopamine levels within prefrontal cortex. Synapse 46: 140-149.

Berridge CW, Waterhouse BD (2003). The locus coeruleusnoradrenergic system: modulation of behavioral state and state-dependent cognitive processes. Brain Res Rev 42: 33-84.

Berridge CW, Wifler K (2000). Contrasting effects of noradrenergic beta-receptor blockade within the medial septal area on forebrain electroencephalographic and behavioral activity state in anesthetized and unanesthetized rat. Neuroscience 97: 543-552.

Bindra D (1968). Neuropsychological interpretation of the effects of drive and incentive-motivation on general activity and instrumental behavior. Psychol Rev 75: 1-22.

Bremer F (1937). Cerebral activity during sleep and narcosis: contribution to the study of the mechanisms of sleep. Bull Acad Roy Med Bel 4: 240-275.

Bushnell MC, Goldberg ME, Robinson DL (1981). Behavioral enhancement of visual responses in monkey cerebral cortex. I. Modulation in posterior parietal cortex related to selective visual attention. J Neurophysiol 46: 755-772.

Buzsaki G, Bickford RG, Ponomareff G, Thal LJ, Mandel R, Gage FH (1988). Nucleus basalis and thalamic control of neocortical activity in the freely moving rat. J Neurosci 8: 4007-4026.

Buzsaki G, Kennedy B, Solt BV, Ziegler M (1991). Noradrenergic control of thalamic oscillation: the role of $\alpha-2$ receptors. Eur $J$ Neurosci 3: 222-229.

Buzsaki G, Leung LW, Vanderwolf CH (1983). Cellular bases of hippocampal EEG in the behaving rat. Brain Res 287: 139-171.

Castaneda E, Whishaw IQ, Robinson TE (1990). Changes in striatal dopamine neurotransmission assessed with microdialysis following recovery from a bilateral 6-OHDA lesion: variation as a function of lesion size. J Neurosci 10: 1847-1854.

Cullinan WE, Zaborszky L (1991). Organization of ascending hypothalamic projections to the rostral forebrain with special reference to the innervation of cholinergic projection neurons. J Comp Neurol 306: 631-667.

Danysz W, Dyr W, Plaznik A, Kostowski W (1989). The effect of microinjections of clonidine into the locus coeruleus on cortical EEG in rats. Pol J Pharmacol Pharm 41: 45-50.

Davis M (1997). Neurobiology of fear responses: the role of the amygdala. J Neuropsychiatry Clin Neurosci 9: 382-402.

De Sarro GB, Ascioti C, Froio F, Libri V, Nistico G (1987). Evidence that locus coeruleus is the site where clonidine and drugs acting at alpha 1- and alpha 2-adrenoceptors affect sleep and arousal mechanisms. Br J Pharmacol 90: 675-685.

De Sarro GB, Bagetta G, Ascioti C, Libri V, Nistico G (1988). Microinfusion of clonidine and yohimbine into locus coeruleus alters EEG power spectrum: effects of aging and reversal by phosphatidylserine. Br J Pharmacol 95: 1278-1286.

España RA, Baldo BA, Kelley AE, Berridge CW (2001). Wakepromoting and sleep-suppressing actions of hypocretin (orexin): basal forebrain sites of action. Neuroscience 106: 699-715.

España RA, Berridge CW (2006). Organization of noradrenergic efferents to arousal-related basal forebrain structures. J Comp Neurol 496: 668-683.

Evarts EV (1960). Effects of sleep and waking on spontaneous and evoked discharge of single units in visual cortex. Fed Proc 19: 828-837.

Feenstra MG, Botterblom MH, Mastenbroek S (2000). Dopamine and noradrenaline efflux in the prefrontal cortex in the light and dark period: effects of novelty and handling and comparison to the nucleus accumbens. Neuroscience 100: 741-748.

Foote SL, Aston-Jones G, Bloom FE (1980). Impulse activity of locus coeruleus neurons in awake rats and monkeys is a function of sensory stimulation and arousal. Proc Natl Acad Sci USA 77: 3033-3037.

Foote SL, Bloom FE, Aston-Jones G (1983). Nucleus locus coeruleus: new evidence of anatomical and physiological specificity. Physiol Rev 63: 844-914.

Gatti PJ, Hill KJ, Da Silva AM, Norman WP, Gillis RA (1988). Central nervous system site of action for the hypotensive effect of clonidine in the cat. J Pharmacol Exp Ther 245: 373-380.

Hobson JA, McCarley RW, Wyzinski PW (1975). Sleep cycle oscillation: reciprocal discharge by two brainstem neuronal groups. Science 189: 55-58.

Isaac SO, Berridge CW (2003). Wake-promoting actions of dopamine D1 and D2 receptor stimulation. J Pharmacol Exp Ther 307: 386-394.

Kuczenski R, Segal DS (1994). Neurochemistry of amphetamine. In: Cho AK, Segal DS (eds). Amphetamine and its Analogues: Psychopharmacology, Toxicology and Abuse. Academic Press: San Diego. pp 81-113.

Kuczenski R, Segal DS (1997). Effects of methylphenidate on extracellular dopamine, serotonin, and norepinephrine: comparison with amphetamine. J Neurochem 68: 2032-2037.

Lagos P, Scorza C, Monti JM, Jantos H, Reyes-Parada M, Silveira R et al (1998). Effects of the D3 preferring dopamine agonist pramipexole on sleep and waking, locomotor activity and striatal dopamine release in rats. Eur Neuropsychopharmacol 8: 113-120.

Makeig S, Inlow M (1993). Lapses in alertness: coherence of fluctuations in performance and EEG spectrum. Electroencephalogr Clin Neurophysiol 86: 23-35.

McCormick DA, Bal T (1997). Sleep and arousal: thalamocortical mechanisms. Annu Rev Neurosci 20: 185-215.

McCormick DA, Pape HC, Williamson A (1991). Actions of norepinephrine in the cerebral cortex and thalamus: implications for function of the central noradrenergic system. Prog Brain Res 88: 293-305.

Metherate R, Cox CL, Ashe JH (1992). Cellular bases of neocortical activation: modulation of neural oscillations by the nucleus basalis and endogenous acetylcholine. J Neurosci 12: 4701-4711.

Mohan KV, Datta S, Chhina GS, Gandhi N, Singh B (1984). Sleep-awake responses elicited from medial preoptic area on application of norepinephrine and phenoxybenzamine in free moving rats. Brain Res 322: 322-325.

Monti JM, Fernandez M, Jantos H (1990). Sleep during acute dopamine D1 agonist SKF 38393 or D1 antagonist SCH 23390 administration in rats. Neuropsychopharmacology 3: 153-162.

Monti JM, Jantos H, Fernandez M (1989). Effects of the selective dopamine D-2 receptor agonist, quinpirole on sleep and wakefulness in the rat. Eur J Pharmacol 169: 61-66.

Moruzzi G, Magoun HW (1949). Brain stem reticular formation and activation of the EEG. Electroencephalogr Clin Neurophysiol 1: 455-473. 
Nishino S, Mao J, Sampathkumaran R, Shelton J, Mignot E (1998). Increased dopaminergic transmission mediates the wake-promoting effects of CNS stimulants. Sleep Res Online 1: 49-61.

O’Donnell P (2003). Dopamine gating of forebrain neural ensembles. Eur J Neurosci 17: 429-435.

Olds J (1962). Hypothalamic substrates of reward. Physiol Rev 42: 604.

Olive MF, Seidel WF, Edgar DM (1998). Compensatory sleep responses to wakefulness induced by the dopamine autoreceptor antagonist (-)DS121. J Pharmacol Exp Ther 285: 1073-1083.

Pape HC, McCormick DA (1989). Noradrenaline and serotonin selectively modulate thalamic burst firing by enhancing a hyperpolarization-activated cation current. Nature 340: 715-718.

Pfingst BE, O’Connor TA, Miller JM (1977). Response plasticity of neurons in auditory cortex of the rhesus monkey. Exp Brain Res 29: 393-404.

Pribram KH, McGuinness D (1975). Arousal, activation, and effort in the control of attention. Psychol Rev 82: 116-149.

Python A, de Saint HZ, Gaillard JM (1996). Effects of a D2 receptor agonist RO 41-9067 alone and with clonidine on sleep parameters in the rat. Pharmacol Biochem Behav 53: 291-296.

Smith AD, Olson RJ, Justice Jr JB (1992). Quantitative microdialysis of dopamine in the striatum: effect of circadian variation. J Neurosci Methods 44: 33-41.

Steinfels GF, Heym J, Strecker RE, Jacobs BL (1983). Behavioral correlates of dopaminergic unit activity in freely moving cats. Brain Res 258: 217-228.

Stellar EM (1954). The physiology of motivation. Psychol Rev 154: 5-22.

Steriade M, Buzsaki G (1990). Parallel Activation of Thalamic and Cortical Neurons by Brainstem and Basal Forebrain Cholinergic Systems. Oxford University Press: Oxford.

Sutcliffe JG, de Lecea L (2002). The hypocretins: setting the arousal threshold. Nat Rev Neurosci 3: 339-349.
Swanson LW, Hartman BK (1975). The central adrenergic system. An immunofluorescence study of the location of cell bodies and their efferent connections in the rat utilizing dopamine-betahydroxylase as a marker. J Comp Neurol 163: 467-505.

Timo-Iaria C, Negrao N, Schmidek WR, Hoshino K, Lobato de Menezes CE, Leme DR (1970). Phases and states of sleep in the rat. Physiol Behav 5: 1057-1062.

Trampus M, Ferri N, Monopoli A, Ongini E (1991). The dopamine D1 receptor is involved in the regulation of REM sleep in the rat. Eur J Pharmacol 194: 189-194.

Trulson ME (1985). Simultaneous recording of substantia nigra neurons and voltammetric release of dopamine in the caudate of behaving cats. Brain Res Bull 15: 221-223.

Trulson ME, Preussler DW (1984). Dopamine-containing ventral tegmental area neurons in freely moving cats: activity during the sleep-waking cycle and effects of stress. Exp Neurol 83: 367-377.

Vanderwolf CH, Robinson TE (1981). Reticulo-cortical activity and behavior: a critique of the arousal theory and a new synthesis. Behav Brain Sci 4: 459-514.

Waterman A, Livingston A, Bouchenafa O (1988). Analgesic effects of intrathecally-applied alpha 2-adrenoceptor agonists in conscious, unrestrained sheep. Neuropharmacology 27: 213-216.

Wisor JP, Nishino S, Sora I, Uhl GH, Mignot E, Edgar DM (2001). Dopaminergic role in stimulant-induced wakefulness. J Neurosci 21: 1787-1794.

Yoshida K, McCormack S, España RA, Crocker A, Scammell TE (2005). Afferents to the orexin neurons of the rat brain. J Comp Neurol 494: 845-861.

Zaborszky L, Cullinan WE, Braun A (1991). Afferent to basal forebrain cholinergic projection neurons: an update. In: Napier TC (ed). The Basal Forebrain. Plenum Press: New York. pp 43-100. 